\title{
Uma Abordagem Utilizando Visão Computacional para Monitoramento de Robôs Móveis em Ambientes de Tarefas na Robótica Educacional
}

\author{
Marcel L. Rios ${ }^{1,2}$, José F. Magalhães Netto ${ }^{2}$ \\ ${ }^{1}$ Instituto Federal de Rondônia - Campus Porto Velho Calama \\ (IFRO) - Porto Velho, RO - Brasil \\ ${ }^{2}$ Programa de Pós-Graduação em Informática - Universidade Federal do Amazonas \\ (UFAM) - Manaus, AM - Brasil \\ marcel.riosdifro.edu.br, jnettodicomp.ufam.edu.br
}

\begin{abstract}
This paper presents an analysis of the robotic behavior through computer vision. The goal is to track the movement of mobile robot in three tasks environments characterized with artificial landmarks to identify areas of interest, serving as a parameter for image processing. A camera positioned at the top, performs image acquisition for a monitoring system, proceeding with the detection of objects of interest and the tracking of mobile robot. The results show the efficiency of the system proposed as a monitoring tool in tasks environments in Educational Robotics in addition to the questionnaire with a survey of opinions of students and teachers.
\end{abstract}

Resumo. Este trabalho apresenta uma análise sobre o comportamento robótico por meio de visão computacional. O objetivo é rastrear os movimentos do robô móvel em três ambientes de tarefas, caracterizados com marcos artificiais para identificação das áreas de interesse, servindo de parâmetro para o processamento de imagens. Uma câmera, posicionada no topo, realiza a aquisição de imagens para um sistema de monitoramento, procedendo com a detecção dos objetos de interesse e com o rastreamento do robô móvel. Os resultados mostram a eficiência do sistema proposto como uma ferramenta de monitoramento em ambientes de tarefas na Robótica Educacional, além do questionário com o levantamento de opinióes dos alunos e dos professores.

\section{Introdução}

A Robótica Educacional já está presente em diversas instituições de ensino e pesquisa, sendo utilizada como um mecanismo para criar um ambiente de ensino mais interessante e atraente, auxiliando na interação entre aluno e professor por meio de ferramentas tecnológicas, construindo conhecimento e possibilitando um ambiente pedagógico que, a princípio, não existia [Zanetti and Bonacin 2014].

O desenvolvimento de atividades de Robótica Educacional envolve a concepção, construção, automação e controle do dispositivo desenvolvido. Realizar atividades pedagógicas com robótica, em algumas escolas, vem se constituindo uma prática, uma forma interdisciplinar de se promover o aprendizado de conceitos curriculares utilizando sistemas robóticos que integram o fazer como meio de aprender [D’Abreu et al. 2011]. 
V Congresso Brasileiro de Informática na Educação (CBIE 2016)

Anais do XXVII Simpósio Brasileiro de Informática na Educação (SBIE 2016)

A Robótica Educacional oferece para o professor e seus alunos um ambiente diversificado, criativo e que pode envolver atividades com vários níveis de dificuldade, de acordo com os ambientes de tarefas. Estes ambientes são caracterizados e possuem regras que devem nortear o comportamento e a trajetória do robô móvel. Porém, tais ambientes carecem de mecanismos para estimar a localização e a trajetória do robô móvel durante a realização de uma determinada tarefa.

A determinação da posição e orientação do robô (pose) pode ser fornecida por diferentes métodos de localização, que podem utilizar desde sensores proprioceptivos elementares como encoders nas rodas e direção, sensores inerciais, sensores absolutos (GPS), sensores externoceptivos (sonares, câmeras, lasers) ou até a combinação (fusão) dessas diferentes fontes sensoriais [Martins et al. 2011].

Sendo assim, este trabalho apresenta uma abordagem utilizando Visão Computacional para analisar o comportamento de robôs móveis em ambientes de Robótica Educacional. Os ambientes de tarefas foram classificados em três categorias: Sumô de Robôs, Robô de Resgate e Viagem ao Centro da Terra. Os ambientes são monitorados por uma câmera posicionada no topo do cenário, que captura as imagens do ambiente de tarefa para um sistema de monitoramento. Em seguida, o sistema realiza o rastreamento do robô móvel, estimando sua trajetória e oferecendo para o professor e alunos uma ferramenta de apoio ao processo de ensino-aprendizado. Os resultados mostraram que o método empregado nesta pesquisa permitiu uma análise mais aprimorada sobre as tarefas, possibilitando maior transparência e compreensão dos desafios propostos.

O restante desse trabalho está organizado da seguinte forma: a Seção 2 apresenta um breve conceito sobre Visão Computacional em Robótica, destacando os principais trabalhos correlatos; a Seção 3 apresenta os materiais e métodos utilizados nesta pesquisa; A Seção 4 apresenta e discute os resultados dos experimentos realizados. Finalmente, a Seção 5 apresenta as conclusões e aponta os trabalhos futuros.

\section{Visão Computacional em Robótica}

A Visão Computacional é uma importante e promissora tecnologia de sensoriamento, aplicada a sistemas robóticos e de automação, uma vez que tenta reproduzir em máquinas um dos sentidos mais complexos, a visão. Os sistemas de visão computacional podem ser implementados em diversas áreas, compostos dos seguintes blocos funcionais: sensoreamento e digitalização da imagem, processamento e análise da imagem e a interação com a aplicação desenvolvida [Vianna 2009].

Na robótica móvel em geral, os métodos que utilizam visão computacional para estimar a posição podem ser divididos em: on-board, quando a câmera é posicionada a bordo do robô, e off-board, quando a câmera é posicionada fora do robô. Esses métodos têm a sua utilização restrita a ambientes pequenos e sem objetos que possam encobrir a visualização do robô, devido ao campo de visão limitado da câmera, como é o caso do futebol de robôs, onde os agentes se movem em uma superfície pequena e plana e a visualização da bola e dos robôs não é obstruída [Carvalho-Filho et al. 2009].

A maioria dos trabalhos que utilizam Visão Computacional em Robótica, não são destinados ao apoio do processo de ensino-aprendizagem na Robótica Educacional. O trabalho de [Queiroz et al. 2015], apresenta a aplicação de um espaço inteligente para 
V Congresso Brasileiro de Informática na Educação (CBIE 2016)

Anais do XXVII Simpósio Brasileiro de Informática na Educação (SBIE 2016)

localizar e controlar um robô móvel. O espaço inteligente é constituído por 11 câmeras, distribuídas em dois laboratórios e no corredor que conecta ambos. Cada câmera está conectada a um servidor de imagem, cuja função é capturar e processar as imagens.

No trabalho de [Andrade et al. 2006], foi desenvolvido um sistema de visão computacional capaz de extrair imagens do ambiente de operação de um robô móvel a partir de duas câmeras e processá-las, a fim de obter informações sobre o robô, tais como sua posição, orientação e detecção de obstáculos. O trabalho de [Araújo et al. 2008], apresenta um sistema de visão que faz o reconhecimento de objetos baseado nas informações de cor e forma, podendo ser utilizado em qualquer situação onde se tem um controle baseado em retroalimentação visual e cujo objetivo consiste em fazer o reconhecimento de um ou mais robôs.

$\mathrm{Na}$ área de Robótica Educacional, poucos trabalhos correlatos foram encontrados. O trabalho de [Costa et al. 2015], teve como objetivo controlar um robô seguidor de linha da plataforma LEGO, de modo que ele percorra uma trajetória utilizando dados coletados por meio do Kinect, identificando a posição do robô no espaço por meio de um algoritmo de reconhecimento de padrões implementado no MATLAB.

O trabalho de [Shimabukuro and Pegoraro 2014], apresenta aspectos do desenvolvimento de um simulador de um ambiente didático com robôs móveis. O ambiente proposto utiliza uma arquitetura cliente-servidor, onde o servidor é responsável pela implementação do sistema de visão computacional e pela comunicação com os robôs. O sistema de visão computacional utiliza as imagens adquiridas de uma câmera com seu plano de imagem paralelo ao solo para identificar a posição e orientação de cada robô.

\section{Materiais e Métodos}

A proposta desse trabalho visa estabelecer as cacterísticas dos ambientes de tarefas para que os desafios de Robótica Educacional possam ser monitorados por meio de visão computacional. A Figura 1 apresenta a visão geral do trabalho proposto, onde um sistema de monitoramento deve receber as imagens capturadas por uma câmera de topo, identificando os marcos artificiais do cenário e rastreando a trajetória do robô móvel no ambiente de tarefa.

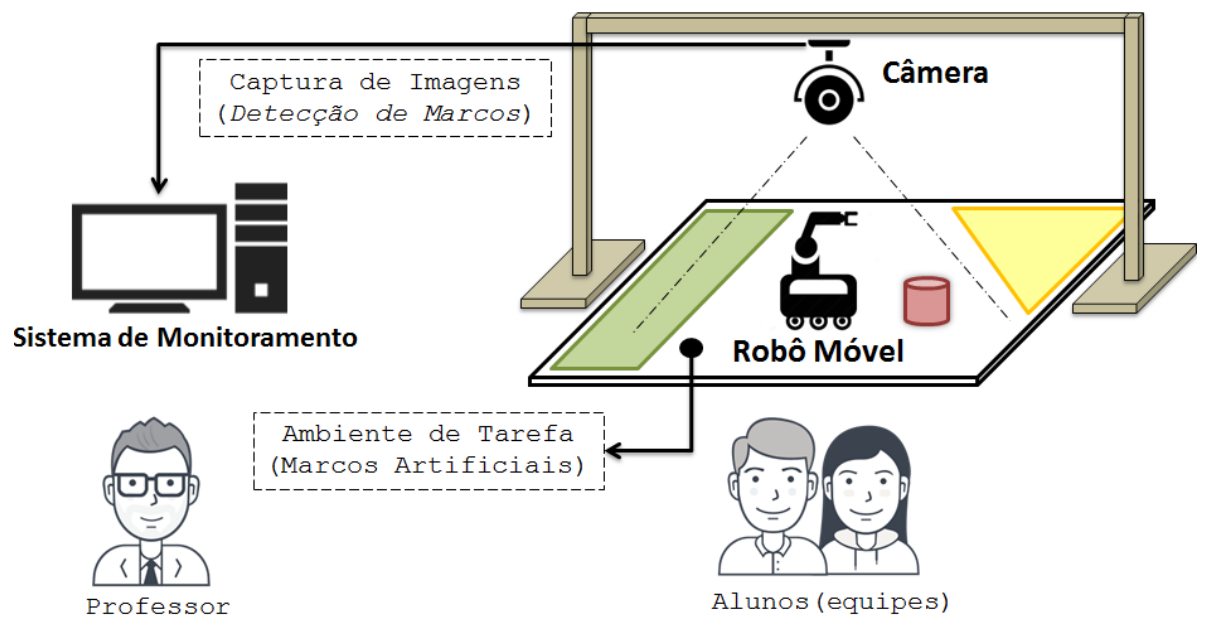

Figura 1. Visão Geral do Sistema Proposto. 
V Congresso Brasileiro de Informática na Educação (CBIE 2016)

Anais do XXVII Simpósio Brasileiro de Informática na Educação (SBIE 2016)

Nesse contexto, após os alunos posicionarem seus respectivos robôs no ambiente de tarefa, o professor pode acompanhar o desenvolvimento da atividade por meio do sistema, que monitora a trajetória do robô móvel. Os desafios propostos foram de adaptados de [Silva 2015]: Sumô de Robôs, Robô de Resgate e Viagem ao Centro da Terra.

O Sumô de Robôs é um desafio no qual dois robôs adversários se empurram com o objetivo de levar o oponente para fora da área estabelecida como arena. A ambiente de tarefa (Figura 2) é uma plataforma circular de $100 \mathrm{~cm}$ de diâmetro, de base branca e circunscrita por uma borda, pintada de preto fosco, de largura entre $2,0 \mathrm{~cm}$ e $3,5 \mathrm{~cm}$.

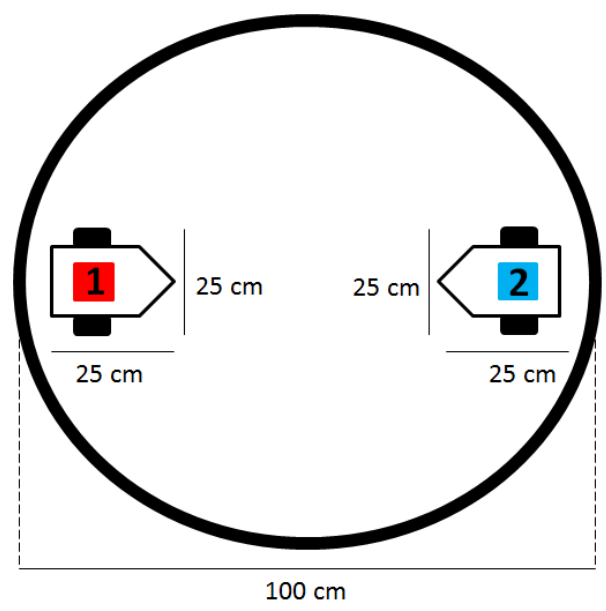

Figura 2. Categoria Sumô de Robôs, adaptado de [Silva 2015].

Conforme demonstra a Figura 2, cada robô (identificado pelos números 1 e 2) deve ser identificado por uma cor distinta (vermelho e azul), possuir dimensões de $25 \mathrm{~cm}$ e pesar, no máximo, $1500 \mathrm{~g}$. A retirada do oponente da arena é o único objetivo desse desafio. Cada partida é dividida em três rounds com duração de, no máximo, 2 (dois) minutos.

O desafio Robô de Resgate, propõe um ambiente de tarefa em que uma vítima precisa ser resgatada e colocada em um local seguro, conforme ilustra a Figura 3.

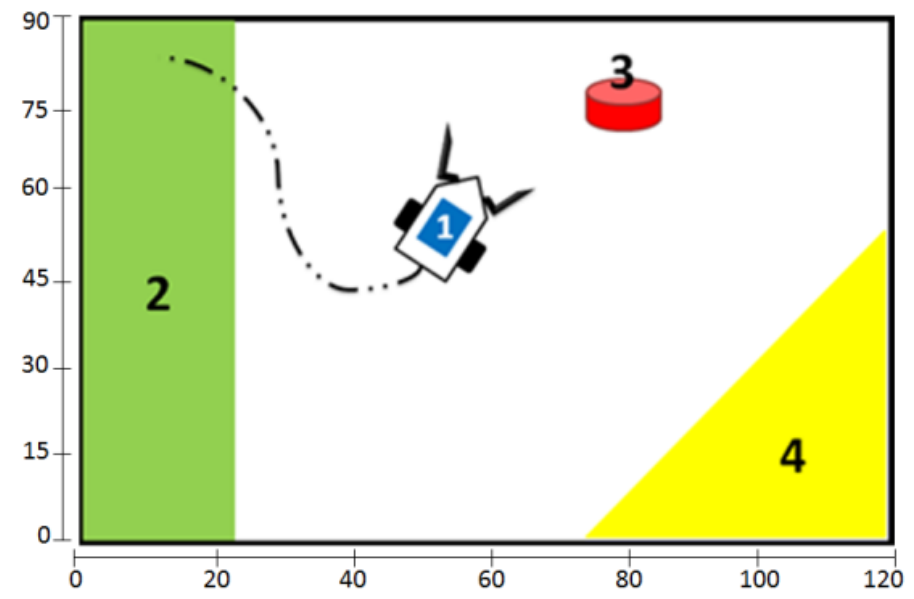

Figura 3. Categoria Robô de Resgate, adaptado de [Silva 2015]. 
V Congresso Brasileiro de Informática na Educação (CBIE 2016)

Anais do XXVII Simpósio Brasileiro de Informática na Educação (SBIE 2016)

Neste desafio, o robô móvel, marcado com a cor azul (identificado pelo número 1), deverá sair do ponto de partida de cor verde (identificado pelo número 2) e percorrer livremente o ambiente com a finalidade de encontrar e realizar o resgate de uma vítima, um objeto cilíndrico estacionário de cor vermelha (identificado pelo número 3). Em seguida, colocá-la em um local seguro, demarcação de cor amarela (identificado pelo número 4).

A pontuação máxima é atingida quando o robô consegue resgatar a vítima e coloca-la no local indicado no cenário. Este ambiente de tarefa é retangular, medindo 90x $120 \mathrm{~cm}$ e o tempo total para a realização desta tarefa é de 5 (cinco) minutos, havendo a possibilidade de calibração de 2 (dois) minutos antes da tarefa.

O desafio Viagem ao Centro da Terra apresenta um caminho considerado conhecido, por onde o robô móvel deve atuar de forma autônoma, com a finalidade de adquirir um artefato (cubo) e retornar à "superfície" inteiro e trazendo o objeto alvo. Conforme demonstra a Figura 4, o robô, marcado com a cor vermelha (identificado pelo número 1), deve seguir o caminho, a partir da posição Cc de entrada, até o centro da espiral, onde deverá capturar um objeto alvo, marcado com a cor azul (identificado pelo número 2). Em seguida, deve retornar com o objeto pelo mesmo caminho até a posição de partida, cumprindo com o desafio.

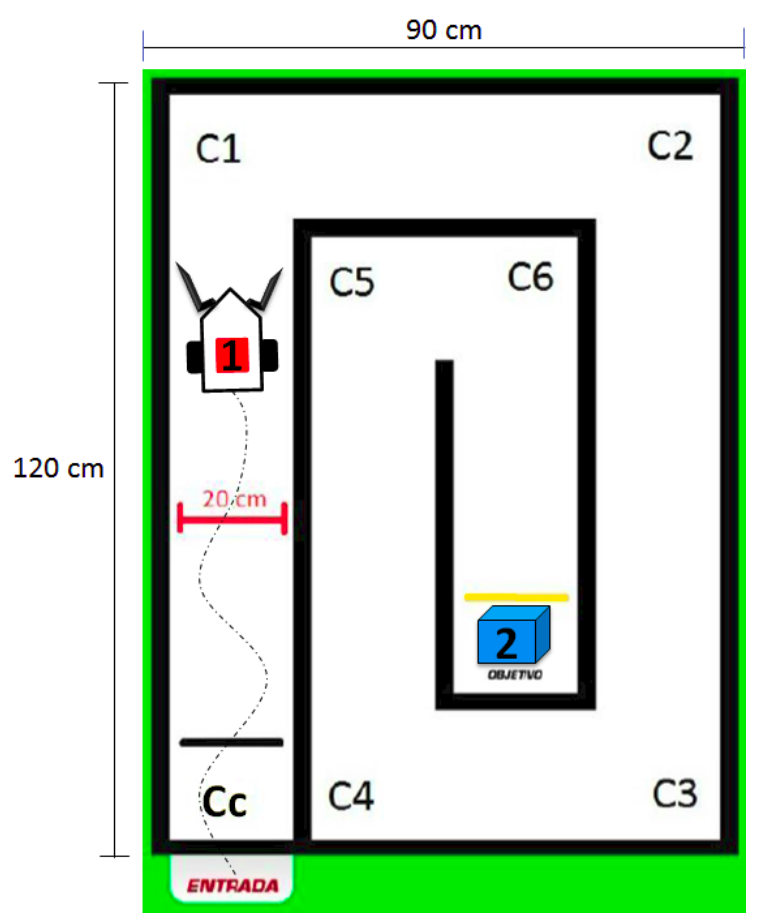

Figura 4. Categoria Viagem ao Centro da Terra, adaptado de [Silva 2015].

Este ambiente de tarefa é retangular e mede $120 \times 90 \mathrm{~cm}$, com um caminho contínuo de $20 \mathrm{~cm}$ de largura, em forma de espiral, pelo qual o robô deverá transitar. A cada curva (C1, C2, C3, C4, C5 e C6) o robô recebe uma pontuação pelo progresso, tanto na trajetória de ida quanto na trajetória de volta. O tempo total para desenvolver este desafio é de 5 (cinco) minutos. O competidor pode optar por calibrar ou não os sensores. Ao fim da calibração, o aluno deverá posicionar seu robô na posição de entrada $(\mathrm{Cc})$ e dar início ao programa do robô. 
V Congresso Brasileiro de Informática na Educação (CBIE 2016)

Anais do XXVII Simpósio Brasileiro de Informática na Educação (SBIE 2016)

A câmera utilizada para o monitoramento da trajetória do robô móvel e dos ambientes de tarefas apresentados, foi uma Webcam 12.Omega Pixels Photo Full HD 1080P, posicionada sobre o cenário, com a finalidade de capturar as imagens durante a realização das tarefas para o sistema de monitoramento.

O sistema de monitoramento, ao receber as imagens obtidas pela câmera, realiza o processo de segmentação, detecção das áreas de interesse e análise dos marcos artificiais existentes. O principal objetivo desse sistema é detectar e rastrear, em tempo real, a cor específica do robô móvel. Após identificar o marco artificial correspondente, o algoritmo realiza o rastreamento robótico a medida em que ele se movimenta, retornando para o professor e alunos uma estimativa da trajetória percorrida pelo robô móvel no ambiente de tarefa.

O presente trabalho foi desenvolvido utilizando a biblioteca OpenCV (Open Source Computer Vision Library) versão 2.4.13 inicialmente integrado a linguagem de programação $\mathrm{C}++\mathrm{e}$, posteriormente, novos testes foram feitos com a linguagem Python.

\section{Resultados e Discussão}

Os resultados desta pesquisa estão organizados em duas subseções: Análise dos Experimentos, apresentando os resultados do experimentos práticos realizados por meio dos materiais e métodos propostos; e Questionário de Pesquisa, apresentando as opiniões dos professores e alunos sobre a perspectiva do sistema e dos ambientes de tarefas propostos.

\subsection{Análise dos Experimentos}

Os experimentos tiveram como objetivo investigar a eficiência do sistema de monitoramento, que utiliza descritores baseados em cor, para analisar as informações estabelecidas em cada ambiente de tarefa. A função do sistema consiste em identificar e localizar as cores de cada marco artificial, inclusive as do robô móvel, utilizando-as como parâmetro para analisar o comportamento robótico.

Uma instância da trajetória estimada por visão computacional do percurso realizado pelos dois robôs móveis no desafio Sumô de Robôs, pode ser observada através da Figura 5.

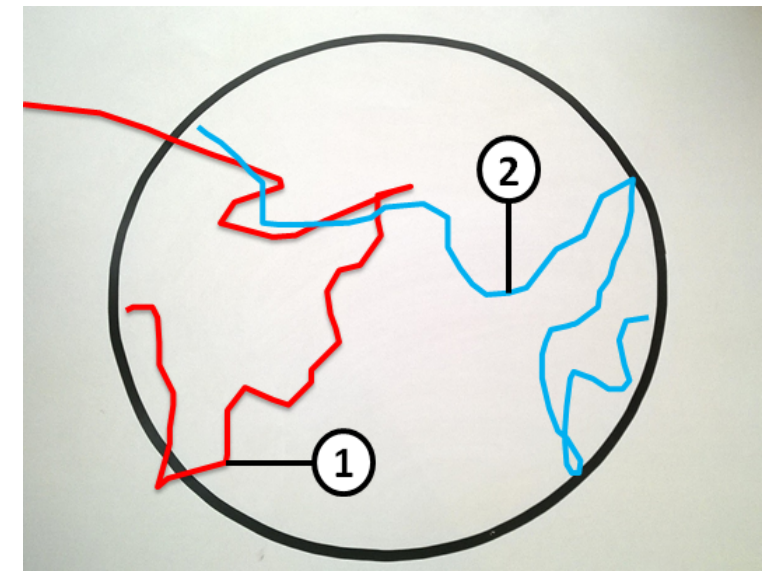

Figura 5. Instância da Trajetória Estimada no Desafio Sumô de Robôs. 
V Congresso Brasileiro de Informática na Educação (CBIE 2016)

Anais do XXVII Simpósio Brasileiro de Informática na Educação (SBIE 2016)

Conforme demonstra a Figura 5, a trajetória em vermelho (identificado pelo número 1) representa o percurso realizado pelo primeiro robô, cujo mesmo utilizou uma marcação de cor vermelha para o monitoramento. A trajetória em azul (identificado pelo número 2) representa o percurso realizado pelo segundo robô, cujo mesmo utilizou uma marcação de cor azul. Nessa instância, é possível constatar que o robô vermelho saiu da arena de sumô em função do confronto com o robô azul.

Neste desafio, o sistema constantemente verifica a movimentação das cores em vermelho e em azul (pertencentes a cada robô móvel) com o objetivo de mapear a movimentação desses robôs durante o desafio. Compreender o comportamento dos robôs móveis na arena de competição, possibilita aos estudantes desenvolver algoritmos cada vez mais estratégicos, visando surpreender o adversário.

Uma instância da trajetória estimada para o desafio Robô de Resgate pode ser observada através da Figura 6, onde a trajetória do robô móvel é representada pela cor azul (identificado pelo número 1) e a trajetória da vítima é representada pela cor vermelha (identificado pelo número 3 ).

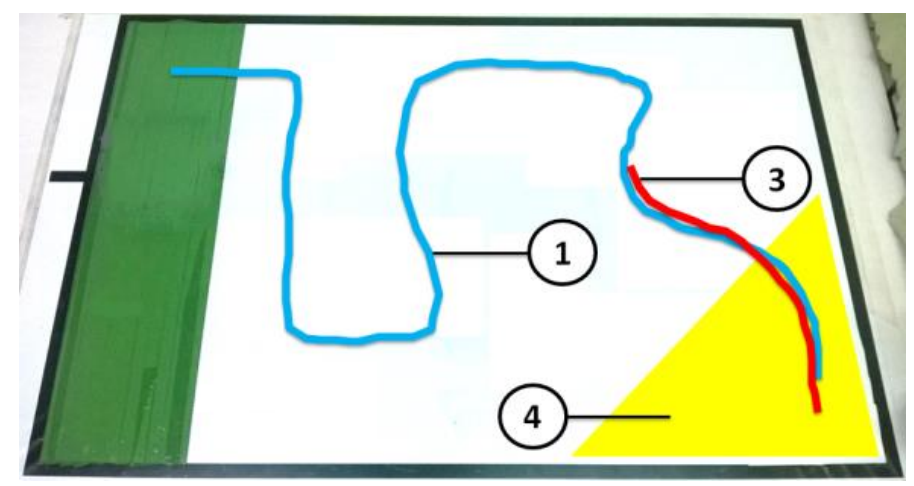

Figura 6. Instância da Trajetória Estimada no Desafio Robô de Resgate.

Neste desafio, o sistema constantemente verifica a movimentação da cor azul (pertencente ao robô móvel), bem como, a movimentação da cor vermelha (pertencente a vítima). O rastreamento permite identificar quando e de que forma a vítima foi conduzida para o local seguro, demarcado pela cor amarela (identificado pelo número 4), sendo esta a condição necessária para o cumprimento desta tarefa.

Por fim, uma instância da trajetória estimada para o desafio Viagem ao Centro da Terra pode ser observada através da Figura 7. É possível constatar que a trajetória em vermelho (identificado pela letra A) representa o percurso realizado pelo robô móvel durante o procedimento de ida ao "Centro da Terra". A trajetória em azul (identificado pela letra B) representa o percurso realizado pelo objeto alvo (cubo) no procedimento de retorno do robô móvel para a posição de entrada.

Neste desafio, o sistema constantemente verifica a movimentação da cor vermelha (pertencente ao robô móvel), bem como, também verifica a movimentação da cor azul (deduzindo que o robô está carregando o objeto alvo, o cubo azul). O rastreamento permite estimar a trajetória realizada pelo robô móvel e do cubo azul, permitindo compreender as dificuldades encontradas pelo robô em sua viagem ao "Centro da Terra". 
V Congresso Brasileiro de Informática na Educação (CBIE 2016)

Anais do XXVII Simpósio Brasileiro de Informática na Educação (SBIE 2016)

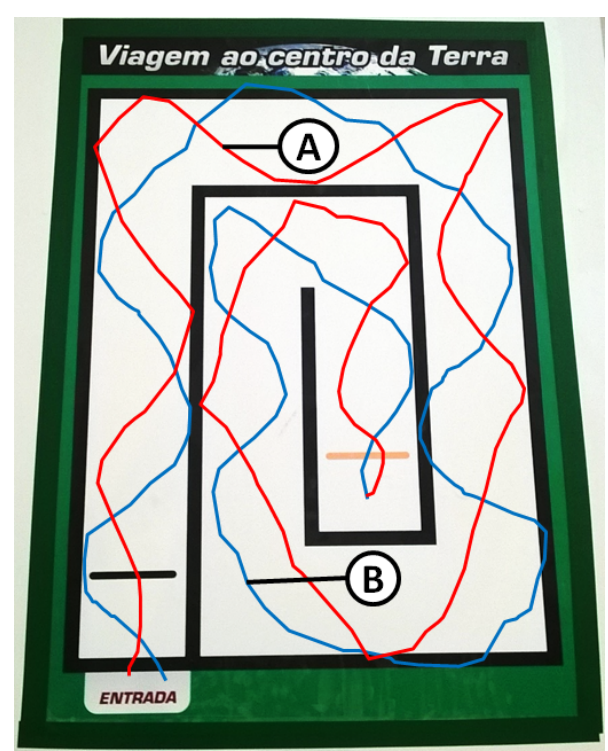

Figura 7. Instância da Trajetória Estimada no Desafio Viagem ao Centro da Terra.

\subsection{Questionário de Pesquisa}

O questionário de pesquisa foi aplicado com a finalidade de compreender o impacto da abordagem proposta, avaliando as opiniões dos alunos e dos professores em dois quesitos: o primeiro sobre a perspectiva do sistema de monitoramento e o segundo sobre os ambientes de tarefas propostos.

Quanto ao primeiro quesito, da amostra de 54 entrevistados: 46,3\% acharam interessante, pois o sistema pode apoiar professor e alunos durante a execução da atividade no ambiente de tarefa; $27,8 \%$ acharam excelente, pois o sistema, além de monitorar o comportamento robótico, pode gerar informações relevantes sobre a tarefa realizada; $24,1 \%$ acharam razoável, pois o sistema realiza as mesmas observações do professor no local; e 1,9\% acharam desnecessário a utilização do sistema proposto. A Figura 8 apresenta o gráfico estabelecido sobre o sistema de monitoramento.

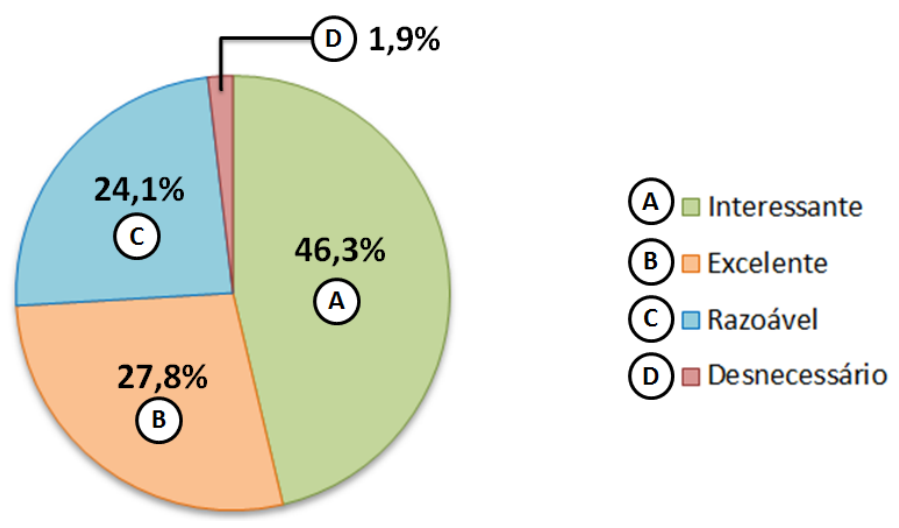

Figura 8. Gráfico com Levantamento de Opiniões - Sistema de Monitoramento.

Quanto ao segundo quesito, da mesma amostra de 54 entrevistados: 94\% disseram que os ambientes de tarefas monitorados instigam o aprendizado e $6 \%$ disseram não incitar aprendizado adicional; $86 \%$ disseram estar satisfeitos com as características do 
V Congresso Brasileiro de Informática na Educação (CBIE 2016)

Anais do XXVII Simpósio Brasileiro de Informática na Educação (SBIE 2016)

ambientes de tarefas e $14 \%$ disseram que os ambientes podem ser aprimorados e customizados; por fim, $91 \%$ disseram sentir-se motivados com os ambientes propostos e $9 \%$ consideraram normal. A Figura 9 apresenta o gráfico estabelecidos sobre os ambientes de tarefas.

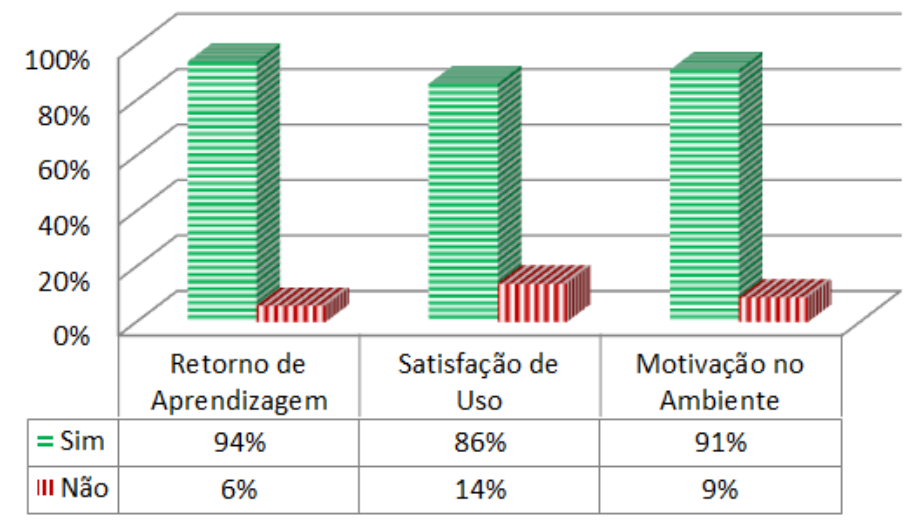

Figura 9. Gráfico com Levantamento de Opiniões - Ambientes de Tarefas.

\section{Conclusões}

Este trabalho buscou avaliar não apenas o comportamento do robô móvel, mas sim identificar as competências/habilidades dos alunos em compreender o problema proposto e solucioná-lo através da programação do robô móvel. O sistema, ao analisar o comportamento do robô, estabelece uma verificação automática da solução apresentada pelo aluno para aquele tipo de desafio (problema). O objetivo foi criar um ambiente inteligente em que docentes e discentes possam trocar conhecimentos, identificar as deficiências de projetos, aprimorar as soluções e contribuir para a integração da robótica nas práticas educacionais.

A partir dos questionários, foi demonstrado que a maioria dos usuários têm interesse em utilizar ambientes de tarefas monitorados, facilitando a compreensão das dificuldades enfrentadas pelo robô móvel na realização das atividades. Os resultados mostraram que a aplicabilidade da abordagem proposta permite que o trabalho se torne flexível para atender diversas demandas educacionais nas áreas da Robótica e Visão Computacional. Sendo assim, a proposta apresentada neste trabalho pode ser integrada com projetos pedagógicos de Cursos Técnicos e Superiores, bem como, pode ser adaptado para o Ensino Fundamental e Médio.

A metodologia adotada contempla cenários controlados, ou seja, ambientes determinísticos em que a única variação decorre da movimentação do robô móvel. Nesse aspecto, uma das limitações desse trabalho está relacionada ao ambiente estático, representado por cores. Os resultados dos experimentos, com o sistema de monitoramento, demonstraram que a estimativa de trajetória e rastreamento robótico é interessante, porém uma análise estatística e acurada sobre o desempenho do robô móvel, no ambiente de tarefa, precisa ser desenvolvida.

Os trabalhos futuros serão destinados ao estudo de outras possiblidades de aplicação, determinando outros ambientes de tarefas, fazendo uso de descritores de formas para identificação do robô móvel ou ainda para caracterizar os marcos artificiais do 
V Congresso Brasileiro de Informática na Educação (CBIE 2016)

Anais do XXVII Simpósio Brasileiro de Informática na Educação (SBIE 2016)

cenário sem a necessidade de utilizar cores. Consequentemente, novas métricas serão estabelecidas com a finalidade de configurar os ambientes de tarefas para explorar diversas possibilidades no processo de ensino-aprendizagem da Robótica Educacional.

\section{Referências}

Andrade, B., Matos, L., and Freire, E. (2006). Um Sistema de Visão Computacional para Robôs Móveis. XXVI Congresso da SBC.

Araújo, G., Mendonça, M., and Freire, E. (2008). Reconhecimento Automático de Objectos Baseado em Cor e Forma para Aplicações em Robótica. XVII Congresso Brasileiro de Automática.

Carvalho-Filho, J., Molina, L., Bensebaa, K., Carvalho, E., and Freire, E. (2009). Estimação de Posição e Orientação para Robôs Móveis. Simpósio Brasileiro de Automação Inteligente - SBAI.

Costa, Y., Hilário, R., Meireles, P., Souza, J., Lopes, C., and Cocota Júnior, J. (2015). Implementação de Algoritmo de Reconhecimento de Padrões para Orientação de um Robô da Plataforma LEGO @ Utilizando Kinect $@$. Workshop de Robótica Educacional - WRE, pages 64-69.

D’Abreu, J., Mirisola, L., and Ramos, J. (2011). Ambiente de Robótica Pedagógica com Br_GOGO e Computadores de Baixo Custo: Uma Contribuição para o Ensino Médio. Simpósio Brasileiro de Informática e Educação - SBIE, pages 100-109.

Martins, R., Bueno, S., Mirisola, L., Paiva, E., and Ferreira, P. (2011). Localização em Robótica Terrestre: Fusão Entre Odometria por Múltiplos Encoders e GPS. Simpósio Brasileiro de Automação Inteligente - SBAI, pages 1043-1048.

Queiroz, F., Covre, V., Fernandes, M., Pereira, F., Vassallo, R., and Bastos-Filho, T. (2015). Localização e Guiagem de Um Robô Móvel em Um Espaço Inteligente. Simpósio Brasileiro de Automação Inteligente - SBAI.

Shimabukuro, M. and Pegoraro, R. (2014). Simulador do Ambiente Educacional Didático de Robôs Móveis - AEDROMO. Workshop de Robótica Educacional - WRE, pages 73-78.

Silva, L. R. (2015). Torneio Juvenil de Robótica: Difundir Desafios Sempre. http://torneiojrobotica.org/sp/. Acessado em: 07-03-2016.

Vianna, M. E. (2009). Calibração de Sistemas de Visão Computacional para Aplicação em Automação e Robótica. Dissertação (Mestrado em Engenharia Mecânica) - Pontífica Universidade Católica de Minas Gerais. [Orientador: Denilson Laudares Rodrigues].

Zanetti, H. and Bonacin, R. (2014). Uma Metodologia Baseada em Semiótica para Elaboração e Análise de Práticas de Ensino de Programação com Robótica Pedagógica. Simpósio Brasileiro de Informática na Educação - SBIE, pages 1233-1242. 